\title{
Forensic features of fatal self photography or "selfies"
}

\author{
Roger W. Byard ${ }^{1}$ (iD
}

Accepted: 20 December 2018 / Published online: 16 January 2019

(C) Springer Science+Business Media, LLC, part of Springer Nature 2019
In 2013 the Oxford English Dictionary had "selfie" as its word of the year, referring to the phenomenon of self or group photography using smart phones or webcams followed by uploading of the images to the internet [1]. The selfie has been defined as a "self-generated digital photographic portraiture spread primarily via social media" [2]. While the behavior in itself may be quite harmless, the need for certain individuals to mark every step of their lives with a photograph sometimes borders on the obsessive. This of course may reach alarming proportions in major world tourist sites where individuals and groups often spend most of their time moving from one selfie vantage point to another without actually looking at their surrounds. Their selfie sticks almost reach the status of weaponry in allowing them to claim space at crowded venues; the gentle days of the "European tour" sadly appear to be well and truly over. In 2015 it was estimated that 24 billion selfies were uploaded onto Google Photos with the number of selfies on Instagram increasing by a factor of 900 between 2012 and 2104 [3].

There has been considerable discussion on the basis for this behavior, with suggestions that excessive selfie-taking and sharing on social media sites are associated with narcissism and psychopathology [4] representing the "act of an egotistical individual keen on self-promotion" [5]. Alternatively, other authors have more charitably, although possibly less plausibly, suggested that it may instead be a "complex and rich means of communicating one's inner state" [6].

While selfie-taking has been widely written about in nonprofessional literature, there has been relatively little scientific work done on it. For example, while a search of Google in December 2016 for "selfie" revealed 400 million hits, only 22 were registered on PubMed at the same time [6]. Similarly there has been very little work published on the forensic aspects and consequences of this behavior. The report by Šoša in

Roger W. Byard

roger.byard@sa.gov.au

1 School of Medicine, The University of Adelaide, Level 2 Medical School North Building, Frome Road, Adelaide, SA 5005, Australia this issue of FSMP is therefore timely in drawing attention to the possibility of lethal outcomes [7].

Deaths and injury are known to have occurred while individuals have been taking selfies, with a study published in 2017 describing 75 deaths that were "precipitated by the process of self-photography", usually while using a cell phone. The number of cases has been doubling each year, with the mean age of victims being 23.3 years. The majority are male $(82 \%)$ students and/or tourists [1, 4]. A study looking over the time range October 2011 to November 2017 identified 259 fatalities [8]. India was the country that recorded the highest number of these deaths, followed by Russia and the United States. While falls from heights, drowning and rail accidents were the most common types of fatalities, more unusual cases have involved an exploding grenade and being dragged underwater by a walrus [1]. It was suggested that the desire to take the perfect self-portrait is causing people to take extreme measures and more risks to obtain the perfect image. Specific dangerous situations have involved heights, water, roads and vehicles, animals and weapons [9].

As a result of the increasing numbers of selfie-related deaths several governments have introduced measures to address this risk, ranging from a Russian government "Safe Selfie Campaign" to illustrate dangerous selfie-taking situations, to the Indian government's declaration of 16 "no selfie zones" throughout the country $[1,10]$. Tourists have been noted to be at particular risk of injury while taking selfies as they tend to lose their situational awareness and become temporarily distracted. Injuries have resulted from lightning strikes, electrocution, wild animal attacks, muggings, and vehicle/pedestrian accidents [5].

But, it is important to put these cases into perspective. Given that there are an estimated 4.6 billion camera phone users globally [1] it is clear that the number of deaths related to selfie taking represents an infinitesimal fraction of this population. This was emphasized in papers that focused on the "lurid rhetoric "of media reporting of such deaths with quotes such as "guns don't kill people... selfies do" and "selfies have become more dangerous than sharks" [11, 12]. However, although most selfie taking is 
clearly completely safe, there are situations where the possibility of injury or death exists. Features of such cases involve individuals who are exhibiting dangerous behavior with a lack of self-awareness, temporary distraction and loss of balance [4]. Interestingly, the role of drugs or alcohol in initiating this behavior has not been assessed, although one case of a survived fall from a cliff involved prior alcohol consumption [10]. The highest incidence occurs in young males which is not surprising given that their high risk behavior has always made them susceptible to a wide range of lethal accidents completely unrelated to their cell phones [13].

For forensic practitioners the challenge is to be able to correctly identify cases where cell phone usage is directly implicated in deaths, both from the findings at the scene and the autopsy, so that a more accurate profile of these particular types of fatalities can be established, leading to an understanding of the exact incidence. Given that the preponderance of cases involve adolescent and young adult males this phenomenon may, however, be just an extension of established risk taking behavior in this group, with the selfie being merely a new, and certainly uncommon, contributor to this theme.

\section{Compliance with ethical standards}

Ethical approval Not required.

Conflict of interest The author declares that he has no conflicts of interest.

Publisher's note Springer Nature remains neutral with regard to jurisdictional claims in published maps and institutional affiliations.

\section{References}

1. Jain MJ, Mavani KJ. A comprehensive study of worldwide selfierelated accidental mortality: a growing problem of the modern society. Int J Inj Control Saf Promot. 2017;24:544-9.

2. Senft TM, Baym NK. What does the selfie say? Investigating a global phenomenon. Int $\mathrm{J}$ Commun. 2015;9:1588-606.

3. Lamba H, Bharadhwaj V, Vacher M, et al. From camera to deathbed: understanding dangerous selfies on social media. Proc $11^{\text {th }}$ Int AAAI Conf Web Soc Med (ICWSM 2017); 576-9.

4. Dokur M, Petekkaya E, Karadağ M. Media-based clinical research on selfie-related injuries and deaths. Ulus Trav Acil Cerrahi Derg. 2018;24:129-35.

5. Flaherty GT, Choi J. The 'selfie' phenomenon: reducing the risk of harm while using smartphones during international travel. J Travel Med. 2016;23:1-3.

6. Bruno N, Pisanski K, Sorokowska A, Sorokowski P. Understanding selfies. Front Psychol. 2018;9:44.

7. Cuculic D, Šoša I. "Selfie"-related electrocution. Forensic Sci Med Pathol. 2018. https://doi.org/10.1007/s12024-018-0078-4.

8. Bansal A, Garg C, Pakhare A, Gupta S. Selfies: a boon or bane? J Family Med Prim Care. 2018;7:828-31.

9. Kurniawan Y, Habsari SK, Nurhaeni IDA. Selfie culture investigating the patterns and various expressions of dangerous selfies and the possibility of government intervention. Proc $2^{\text {nd }} J$ Govt Pol Int Conf; July 2017:324-32.

10. Mehmood M, McNicholl B. Selfieeeeeeee! Ann Emerg Med. 2017;70:434.

11. Maddox J. "Guns don't kill people ... selfies do": rethinking narcissism as exhibitionism in selfie-related deaths. Crit Stud Media Commun. 2017;34:193-205.

12. Du Preez A. Sublime selfies: to witness death. Eur J Cult Stud. 2018;21:744-60.

13. Byard RW. Accidents. In: Byard RW, editor. Sudden death in the young. 3rd ed. Cambridge: Cambridge University Press; 2010. p. $7-82$. 